\title{
Editorial: Emerging Technologies for Waste Biomass to Energy: Innovations and Research Challenges
}

\author{
Eldon R. Rene ${ }^{1}$, Duc Duong $\mathrm{La}^{2}$ and Dinh Duc Nguyen ${ }^{3,4 *}$ \\ ${ }^{1}$ Department of Water Supply, Sanitation and Environmental Engineering, IHE Delft Institute for Water Education, Delft, \\ Netherlands, ${ }^{2}$ Institute of Chemistry and Materials, Hanoi, Vietnam, ${ }^{3}$ Faculty of Environmental and Food Engineering, Nguyen Tat \\ Thanh University, Ho Chi Minh City, Vietnam, ${ }^{4}$ Department of Environmental Energy Engineering, Kyonggi University, Suwon, \\ South Korea
}

Keywords: process design, optimization, renewable energy, waste biomass, biorefinery, waste to energy technologies

\section{Editorial on the Research Topic}

Emerging Technologies for Waste Biomass to Energy: Innovations and Research Challenges

\section{OPEN ACCESS}

Edited and reviewed by: Uwe Schröder, Technische Universitat Braunschweig, Germany

*Correspondence:

Dinh Duc Nguyen nguyensyduc@gmail.com

Specialty section: This article was submitted to Bioenergy and Biofuels, a section of the journal Frontiers in Energy Research

Received: 01 July 2021

Accepted: 19 July 2021

Published: 02 August 2021

Citation:

Rene $E R, L a D D$ and Nguyen $D D$ (2021) Editorial: Emerging Technologies for Waste Biomass to

Energy: Innovations and

Research Challenges.

Front. Energy Res. 9:734541. doi: 10.3389/fenrg.2021.734541
Considering the rising awareness in global warming, the need for adequate pollution control strategies, rapid industrialization and population growth, it is necessary to prioritize on emerging technologies and processes that accelerate the transition from the use of fossil fuels to the use of renewable energy resources to solve future global energy needs, as well as to protect and/or rehabilitate the natural environment. Thus, energy efficiency and renewable energy technologies are the core elements of that transition, and their synergies play an important role to solve real-world problems, specifically in the developing countries and countries in transition. On the other hand, huge quantities of (solid) waste biomasses are being generated daily around the world by wastewater treatment plants, livestock farms, cattle slaughterhouses, the food industry, agriculture, mountainous regions, etc. The treatment and management of these sources of (solid) waste is an environmental and social challenge facing most nations. However, in another context, these wastes can be considered as essential raw materials for major waste to energy (WtE) projects. In this special issue, five main themes were covered, as shown in Figure 1: 1) modelling of a pyrolysis system, 2) conversion of non-woody lignocellulose biomass to valuable products, 3) solid waste management in the mountains, 4) computational tools for application in biotechnology, and 5) valuable carbonbased materials from biomass.

Due to the lack in simulation-based researches on condensation and fractionation for biomass pyrolysis, Charis et al. modelled a sustainable, self-energized pine dust pyrolysis system with staged condensation for optimal recovery of bio-oil. In this work, the authors made sustainable improvements to a pine dust pyrolysis system in order to eliminate total dependence on external electrical energy supply and improve the yield of high-quality dry bio-oil. Thus, the first (primary) and second (secondary) condenser temperatures were varied separately while keeping the other two constants, using a sensitivity study. After achieving optimum temperatures using the sensitivity analysis, the ChemCAD simulation was run at those constant values to evaluate the overall performance of the simulation. The key performance indicators were the yield (quantity) of the obtained product stream and its water composition (quality). From their modelling results, the authors reported that it was possible to recover $49 \mathrm{~kg} / \mathrm{h}$ of good quality oil ready for use in the fuel oil generators. Besides, it was expected that the plant would be operated for a stipulated time/day so that it can meet the required fuel ratio for powering the generator for a small power grid. Another interesting work has evaluated the potential of the aquatic biomass Phragmites karka grown from 


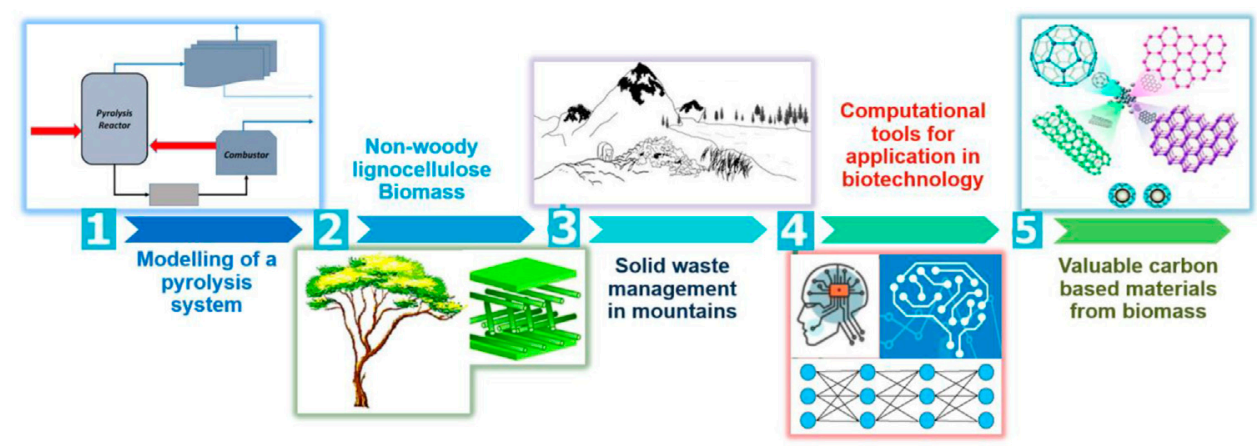

FIGURE 1 | Research innovations in the field of waste to energy conversion - technologies and modelling aspects.

two different lakes as feedstock for biofuel production. The authors Ummalyma et al. carried out enzymatic hydrolysis to ascertain the digestibility of the pre-treated biomass and a detailed characterization study was performed by crystallinity and structural alteration analysis. Besides, fermentation studies for ethanol conversion of the hydrolysate obtained from the biomass were performed using wild yeast cells. In the case of the enzymatic digestibility of Chilika Lake biomass, the maximum reducing sugar yield was $75 \%$ from alkali-treated biomass, carried out at a sonication frequency of $20 \mathrm{kHz}$ for $25 \mathrm{~min}$. After fermentation, the ethanol concentration was 3.4\% with a fermentation efficiency of $78.6 \%$ within $48 \mathrm{~h}$. The authors concluded that, sono-alkaline pre-treatment is superior to the acid pre-treatment process in order to obtain high yields of ethanol.

Hamzah et al. carried out thermal analysis to ascertain the effect of the blending and heating rate of the thermal behaviour of Malaysian bituminous coal (Silantek), oil palm biomass (empty fruit bunch, EFB), and their blends using thermogravimetric analysis. The main aim of that study was to provide an insight into the suitability of utilizing agriculture residue such as oil palm residue along with a high rank coal for a thermal application, which in turn could reduce the impact on the environment as a result of the waste disposal and combustion of fossil fuel (coal). Concerning the thermal behaviour, it was shown that Silantek coal (SC) contains high fixed carbon (FC), low volatile matter (VM), unlike EFB which has high volatile matter (VM) and low FC. Besides, SC was shown to have a carbon content of $74.7 \%$, while EFB contained only $42 \%$ of carbon. Furthermore, the authors reported the following interesting results: 1) heating rate affected the thermal behaviour of the fuel causing temperature shifts to higher temperatures as the heating rate increases, and 2) the blended fuels demonstrated higher degree of interactions during co-pyrolysis. Owonubi et al. reviewed the different extraction procedures involved in the conversion of non-woody biomass to high $\mathrm{C}$ containing nanocellulose particles. The authors provided sufficient literature-based discussions on the chemistry behind the different extraction steps, namely: 1) dewaxing of the fiber, 2) mercerization or alkalization, 3) bleaching, 4) acid hydrolysis or depolymerization, and 5) isolation. As the properties of the cellulose nanoparticles
(CNPs) depend greatly on the extraction and isolation processes, the authors identified the following four major factors that affect or influence their production process: 1) the amount of hemicellulose and lignin present in the fiber, 2) the percentage (\%) of cellulose after purification of the fiber, 3) plant part to be used in the isolation of CNP, and 4) the proposed application of the extracted $\mathrm{CNP}$ and expected properties of the CNP.

Thakur et al. mentions that solid waste management (SWM) is challenging in the highlands (i.e., the mountains) due to their remoteness, topographical configuration, increasing urbanization, and harsh climate compared to the plain areas. In their review, the authors highlighted the current status of waste generation, the current SWM practices, and SWM challenges in the eco-sensitive Indian Himalayan region (IHR). The review also discussed the possible resource recovery from waste in the IHR, corrective measures introduced by the government specific to IHR and, the way forward for improved SWM for achieving sustainable development of the IHR. The following key points were highlighted in their review: 1) the waste generated in IHR is inconsistent throughout the year as tourist inflow varies in summers and winters, which burdens the otherwise afflicted waste collection, transportation, treatment, and disposal facilities, 2) door-to-door garbage collection systems have been employed with the collaboration of the informal sector, private agency, non-government organizations (NGOs), housing society, through tipper trucks, dumper placers, and open body trucks, 3) waste collectors, rag pickers, and street sweepers are involved in collecting and transportation of waste to the respective disposal sites where the lack of worker's protective equipment and their ignorance have led to various occupational health-related hazards, 4) there are only 15 composting units, three vermicomposting, three biogas, and $2 \mathrm{RDF} /$ pelletization facilities operational in IHR states treating $0.413 \mathrm{MT} / \mathrm{Y}$ of MSW, 5) the collected MSW is dumped at the disposal sites on open unused lands or hill slopes, 6) the freezing conditions in the IHR pose a technical challenge for efficient composting and sometimes may even lead to the failure of the composting process in the cold hilly regions, and 7) the different resource recovery from waste to 
energy (WtE) facilities (composting/vermicomposting, anaerobic digestion, RDF, and gas recovery from landfills) and safe residual waste disposal through sanitary landfills are some of the possibilities that must be explored proficiently for IHR.

Heidari et al. reported a novel bio-computational machine based on particle physics via the intersection of computation, wastewater, and microorganisms that aims to introduce the novel bio-computational machine based on particle physics. Interestingly, this novel research line focused on investigating the mixture of the microbial fuel cells, specifically "Spirulina" micro-algae, and household chores greywater to propose highprecise fluid simulation that enables output energy control, flow, and management of the type of solution mix, by transferring the data from the modules to the computational environment. According to the authors, the signals were stored in a local digital database, and it was later combined with the particle physics engine to simulate the materials' behaviour, thereby providing the opportunity to control the state variables digitally. In another resource recovery-based study, Khairol Anuar et al. evaluated the properties of the C-dots, focusing on the fabrication of C-dots, characterization methods, as well as the applications of C-dots, prepared using various forms of biomass as the carbon source(s). The authors have provided a detailed evaluation and a critical review on the fundamental understanding of C-dots, including their structure analysis, physical and chemical properties. Besides, the most important factors affecting the bandgap of the C-dots and the strategies to overcome these shortcomings are also discussed in their report.
Thus, considering the world's energy demand crisis, waste management and disposal, global warming, and fossil fuel depletion, this special issue addresses the important environmental issues and offers advanced solutions or orientations to simultaneously reduce waste biomass and create a sustainable energy source. The guest editors of this special issue firmly believe that the papers will be a useful reading document to your research group and we wish you all the very best.

\section{AUTHOR CONTRIBUTIONS}

ER: Writing - original draft DL: Writing - review \& editing DN: Supervision, Writing - review \& editing.

Conflict of Interest: The authors declare that the research was conducted in the absence of any commercial or financial relationships that could be construed as a potential conflict of interest.

Publisher's Note: All claims expressed in this article are solely those of the authors and do not necessarily represent those of their affiliated organizations, or those of the publisher, the editors and the reviewers. Any product that may be evaluated in this article, or claim that may be made by its manufacturer, is not guaranteed or endorsed by the publisher.

Copyright $\odot 2021$ Rene, La and Nguyen. This is an open-access article distributed under the terms of the Creative Commons Attribution License (CC BY). The use, distribution or reproduction in other forums is permitted, provided the original author(s) and the copyright owner(s) are credited and that the original publication in this journal is cited, in accordance with accepted academic practice. No use, distribution or reproduction is permitted which does not comply with these terms. 